proper use are gradually beginning to trickle through.

It would be invidious to select for praise or criticism any particular chapter in a book of high attainment which must be judged as a whole. The writers are to be commended on the high standard attained in the presentation of their subjects. The editors are to be congratulated in achieving so much uniformity from a varied field, and the publishers for their enterprise and excellent production. To post-graduate surgeons, and those engaged on war work, at home and in the forces, this book will provide interesting and stimulating reading, and form a sound nucleus to guide their surgical endeavours.

\section{CATECHISM SERIES}

\section{SURGERY}

(Fifth Edition)

Parts 3, 4 and 5.

\section{ANATOMY}

(Fifth Edition)

Part 5. The Thorax, by C. R. Whitaker, F.R.C.S.E. F.R.S.E. E. \& S. Livingstone, Edinburgh. I943. Price Is. 6d. each part.

One of the most astounding things in life is the variations that occur in the minds of individuals. There are apparently no two absolutely identical people in this world. Every one has his own individuality which appears to be personal to him and his own true possession. At an early stage in one's medical career it is important to find out how you can learn best. Are you an audito receptive person? Do you learn by hearing things said? Are you visuo-receptive! Do you learn by diagrams, by reading and by seeing things? There are, of course, many other classes into which you may fit. To those who learn best by catechism these books are an extraordinarily helpful asset. To those who don't they are of little value. Part V, Anatomy (Thorax), 5th edition, covers the ground needed for the 2nd M.B. examination.

Part 3, Surgery, covers the abdominal wall, peritoneum, hernia, stomach and duodenum, intestinal obstruction, liver, appendix, gall bladder, pancreas, spleen, rectum, and anus.

Part 4, The Genito-urinary system, thorax, breast, muscles, and sympathetic nervous system.

Part 5, Scalp, cranium, face, neck, oesophagus, upper and lower limbs. Index.

\section{THE PRACTICE OF LOCAL ANAESTHESIA}

By George Bankoff. William Heinemann, London. 1943. Price 17 s. 6d.

In writing this book Mr. Bankoff has attempted to remedy a long-standing want for a manual on local anaesthesia. The various techniques are described and the text is profusely illustrated. A notable and unfortunate omission is the Patrick method of brachial plexus block: this modification, even in the hands of the inexperienced, ensures practically roo per cent success in obtaining analgesia of the upper extremity.
The possibilities inherent in the combination of local anaesthesia with light general narcosis are mentioned, but are not stressed as the method of choice to which there are few contra-indications. Such a combined technique ensures the maximum of comfort to the patient and the minimum of psychic trauma and possible shock.' But Mr. Bankoff, apparently, has little confidence in the ability of his anaesthetists. "The competent surgeon must be well acquainted with the different types of anaesthesia in order that he may select the best. . . . Only in this way can an anaesthetic be administered without danger," he says. This may be a necessary and excellent principle for continental surgeons working in their own countries: the standard of anaesthesia abroad is notoriously low, and the specialist anaesthetist practically unknown, but surely in this country such practice savours of keeping a dog and yet doing one's own barking.

\section{FRACTURES AND JOINT INJURIES}

By R. Warson-Jones, M.Ch.Orth., F.R.C.S. Third Edition, Vol. I. E. \& S. I.ivingstone, Edinburgh. 1943. Price 75s. per set of two volumes.

The fact that the first edition of th is work appeared in 1940, the second edition in 1941-and was reprinted - and that the third edition appears in 1943 , is sufficient testimony to the value placed upon this book by students and surgeons.

The present edition, of which, so far, only Vol. I is available, is beautifully got up, new illustrations in colour have been added, and the novel method of demonstrating radiological pitfalls which has been retained should be carefully studied by both radiologists and surgeons, for it is the surgeon who is held responsible for the failure of treatment of a fracture, even if inadequate $\mathrm{X}$-ray pictures are the primary cause of the failure. Even now in some hospitals hip joints are only X-rayed in one plane. Surely Fig. 274 should demonstrate the folly of this. I would therefore commend Chapter VIII to surgeons and radiologists alike.

A considerable revision and rearrangement has been effected in this new edition, and much new material added without much loss of old friends, though I was sorry to see the disappearance of the anatomical drawings and surface markings of the back in connection with myofascial injuries, which I found most useful in diagnosis and treatment.

The only serious fault I have to find with this work is the lack of an index. No doubt this will appear in Vol. II when this is available, but such an arrangement is inconvenient. The best arrangement was that adopted in a popular text-book of surgery which appeared for a time in two volumes, each of which contained a full index covering both volumes, the pages of which numbered on from volume one consecutively into volume two.

Considering the present difficulties, both the publishers and the author are to be congratulated on issuing this volume in a really fine pre-war style.

Watson-Jones's "Fractures" has become a surgical classic, and it is in the expectation of many future editions that I venture to make these minor constructive criticisms of this very readable and attractive work, which no civil or military surgeon or hospital resident should be without. 